\title{
The International Classification of Functioning, Disability, and Health (ICF): Are We Using the Correct language?
}

\section{Mohamed Abdelmegeed ${ }^{1,2 *}$}

${ }^{1}$ Department of Physical Therapy, School of Allied Health Professions, Loma Linda University, California, USA ${ }^{2}$ Department of Orthopedic Physical Therapy, Cairo University, Egypt

\section{Commentary}

The development of biopsychosocial health models has been evolving over the years from Nagi's disablement model in 1960s [1], to the International Classification of Disease (ICD) in 1980s [2], to the International Classification of Functioning, Disability, and Health (ICF) in 2001 [3]. Since the ICF model was approved by the World Health Organization (WHO) in 2001 [3], numerous research studies tried to validate its usage in different health conditions, just to mention some examples here such as its application on patients with Dupuytren's disease [4], systemic sclerosis [5], cold sensitivity [6], carpal tunnel syndrome [7], hand osteoarthritis [8], and severe hand injures [9]. Moreover, other researchers and organizations tried to derive subcategories from the main ICF model to build new sub-models such as the Brief ICF Core Set for Hand Conditions [10], ICF for children and youth (ICF-CY) [11].

The American Physical Therapy Association (APTA) has established research groups to develop clinical practice guidelines of different health conditions and to link them to the ICF model [12]. Most of these guidelines have substantiated the use of the ICF model in clinical practice and based on these guidelines, most of the classification of diseases and health conditions using the ICF model has grade " $\mathrm{A}$ " level of evidence. It can be concluded from those published guidelines that the ICF should be endorsed as a common physical therapy language. Although the WHO [3] indicated that the combined use of the ICD and the ICF provides a more thorough picture of health conditions, the ICF model is not yet used clinically and is only studied in research papers. I think we should ask ourselves why this is happening and know the barriers.

Here in the United States, physical therapists still cannot use the ICF terminologies to bill for their services. This may be due to the influence of the physician's lobby on the insurance system which may be bigger and stronger than the physical therapy one, or because the ICD codes are more universal, or due to pitfalls in the ICF model itself, or simply because of the fear of trying a newer version to describe a health condition. Although the physical therapy professional organizations are strong in the United States, they still fail to convince the insurance companies to accept the ICF terminologies to reimburse for physical therapy service. The question remains; can the ICF model be used to replace the currently endorsed ICD model for documenting functioning?

Our understanding is that the ICF model was not established to replace a previous model, rather, it was built to refine the concept of functioning in healthcare, to complement other models, and to eliminate the negative connotation associated with other models' languages such as using "activity limitation" and "participation restriction" in the ICF model instead of using "impairment" and "disability" in Nagi's model. Moreover, the ICF was established to further elaborate on the functioning aspect of a health condition such as documenting that the patient has neck pain and mobility deficits (b7101 mobility of several joints) in the ICF model versus using M43.02 spondylosis, cervical region as an ICD-10 code [13].
In this example, cervical spondylosis seems to be a vague term and does not indicate what is really going on with the cervical spine other than a mere diagnosis term to indicate degeneration in the cervical spine. It does not indicate function or deficits and whether it is associated with motor, sensory, coordination deficits or headache. The ICF came out to breakdown such diagnosis to more informative terminologies; cervical spondylosis, therefore, can be broken down to neck pain with mobility deficits, neck pain with movement coordination deficits, neck pain with headache, neck pain with radiating pain [14].

In a recently published study by the author of this commentary, Abdelmegeed et al. [15] found that the brief ICF Core Set for Hand Conditions useful in describing function in subjects with ulnar wrist pain. They concluded that the brief ICF Core Set for Hand conditions enables a useful systemic process for identifying, documenting, and communicating health status.

Unlike other functioning models and one of the advantages of the ICF model is that it recognizes the importance of the environmental and personal factors which might affect a health condition. Although this is not yet a well-researched topic, Kus et al. [16] used the brief ICF Core Set for Hand Conditions and applied it on a sample of 206 patients with different hand pathologies. They highlighted the significant contribution of the environmental factors and recommended consideration of the identified environmental factor such as e225 climate, e410 individual attitude of immediate family members, e460 social attitudes and other relevant factors when dealing with subjects with hand pathologies. They concluded that the Brief ICF Core Set for Hand Conditions should be used as the standard tool in addressing functioning in subjects with hand conditions [16]

Ptyushkin et al. [17] found that the disadvantages of ICF may include complicated terminology especially if used by public organizations and subjectivity of the assessor. They indicated that the organizations who reported it to have complicated terminologies may lack the appropriate training on how to use it. On the other hand, the participants in their study (professional and public organizations) found that the holistic approach of the ICF helped them to view their clients differently and more comprehensively. It should be noted, however, that they obtained their data from public and professional organizations in Slovenia only [17].

*Corresponding author: Mohamed Abdelmegeed, Department of Physical Therapy, School of Allied Health Professions, Loma Linda University, 24851 Circle Dr. Loma Linda, CA 92350, USA, Tel: +1(909) 583-4966; E-mail: dr.maf_ortho@yahoo.com

Received February 18, 2019; Accepted February 23, 2019; Published February 28, 2019

Citation: Abdelmegeed M (2019) The International Classification of Functioning Disability, and Health (ICF): Are We Using the Correct language? J Neurol Neurophysiol 10: 484. doi:10.4172/2155-9562.1000484

Copyright: (c) 2019 Abdelmegeed M. This is an open-access article distributed under the terms of the Creative Commons Attribution License, which permits unrestricted use, distribution, and reproduction in any medium, provided the original author and source are credited. 
Citation: Abdelmegeed M (2019) The International Classification of Functioning, Disability, and Health (ICF): Are We Using the Correct language? J Neurol Neurophysiol 10: 484. doi:10.4172/2155-9562.1000484

A proper understanding of the ICF model and its terminologies opens a wide range of research studies in physical therapy and rehabilitation and provides a template for evidence-based practice in clinical settings. We think that the use of the ICF model and its derivatives like the Brief ICF Core Set for Hand Conditions is an integral part of the clinical language that should be endorsed by clinicians and therapists. Although researches have been attempted to focus on how ICF might explain health outcomes across different health conditions, more studies are needed to link physical therapy outcome measures to the ICF in different settings (e.g., assessment, treatment) for different health conditions.

\section{References}

1. Nagi SZ (1964)A study in the evaluation of disability and rehabilitation potential: Concepts, methods, and procedures. Am J Public Health 54: 1568-1579.

2. World health organization (1980) International classification of impairments, disabilities, and handicaps: A manual of classification relating to the consequences of disease, published in accordance with resolution WHA29. 35 of the Twenty-ninth World Health Assembly.

3. (2001) World Health Organization. International classification of functioning, disability, and health (ICF); Geneva, Switzerland.

4. Pratt AL, Byrne G (2009) The lived experience of dupuytren's disease of the hand. J Clin Nurs 18: 1793-1802.

5. Rubenzik TT, Derk CT (2009) Unmet patient needs in systemic sclerosis. J Clin Rheumatol 15: 106-110.

6. Carlsson IK, Edberg AK, Wann-Hansson C (2010) Hand-injured patients experiences of cold sensitivity and the consequences and adaptation for daily life: A qualitative study. J Hand Ther 23: 53-61.

7. Jerosch-Herold C, Mason R, Chojnowski AJ (2008) A qualitative study of the experiences and expectations of surgery in patients with carpal tunnel syndrome. J Hand Ther 21: 54-61.
8. Stamm T, van der Giesen F, Thorstensson C (2009) Patient perspective of hand osteoarthritis in relation to concepts covered by instruments measuring functioning: A qualitative european multicentre study. Ann Rheum Dis 68: 14531460.

9. Williams AE, Newman JT, Ozer K Juarros A, Morgan SJ, et al. (2009) Posttraumatic stress disorder and depression negatively impact general health status after hand injury. J Hand Surg 34: 515-522.

10. Rudolf K, Kus S, Chung KC, Johnston M, LeBlanc M, Cieza A, et al. (2012) Development of the international classification of functioning, disability and health core sets for hand conditions-results of the world health organization international consensus process. Disability \& Rehabilitation 34: 681-693.

11. (2007) World health organization. International classification of functioning, disability, and health: Children and youth version, ICF-CY, Geneva, Switzerland.

12. (2000) American Physical therapy association. Clinical research agenda for physical therapy. Physical Therapy 80: 499-513.

13. (2003) World health organization. International statistical classification of diseases and related health problems 10: 10.

14. Peter RB (2017) Neck pain: Clinical practice guidelines linked to the international classification of functioning, disability, and health from the orthopedic section of the American Physical therapy association. J Orthop Sports Phys Ther 47: 1-83.

15. Abdelmegeed M, Lohman E, Daher N, Syed HM (2019) Linking physical therapy outcome measures to the Brief international classification of functioning core set for hand conditions in subjects with ulnar wrist pain. J Back Musculoskelet 3: $1-9$.

16. Kus S, Oberhauser C, Cieza A (2012) Validation of the brief internationa classification of functioning, disability, and health (ICF) core set for hand conditions. J Hand Ther 25: 274-287.

17. Ptyushkin P, Vidmar G, Burger H, Marinček Č, Escorpizo R (2011) The international classification of functioning, disability, and health (ICF) in vocational rehabilitation and disability assessment in Slovenia: state of law and users' perspective. Disability and rehabilitation 33: 130-136. 